\title{
Spatial cluster and Heterogeneity Research on Energy-Related Carbon Emissions in Districts and Counties of Guangdong Province
}

\author{
Wenxiu Wang, Shangjun Ke, Daiqing Zhao, and Guotian Cai * \\ Guangzhou Institute of Energy Conversion, Chinese Academy of Sciences; Key Laboratory of Renewable Energy, Chinese Academy \\ of Sciences, Guangdong Provincial Key Laboratory of New and Renewable Energy Research and Development, Guangzhou, 510640, \\ China
}

\begin{abstract}
Energy-related carbon emissions in districts and counties of Guangdong province from 2005 to 2016 are researched based on spatial econometrics method in this article, and significance cluster area and heterogeneity area are precise pinpointed. Conclusions are as follows: (1) total carbon emissions and per capita carbon emissions exist significance global spatial autocorrelation in the year 20052016, and formed significance high-high cluster area in districts and counties of Guangzhou city, Shenzhen city and Dongguan city. It also formed three significance low-low cluster areas in districts and counties of eastern, western and northern of Guangdong province. Low-high heterogeneity area and high low heterogeneity area often appears in the scope of high-high cluster area and low-low cluster area. (2)Carbon emission intensity not exist significance global spatial autocorrelation, but exist significance cluster area and heterogeneity area in the ecological development areas of eastern, western and northern of Guangdong province. In the end, the paper puts forward the regional and detailed policy recommendations for efficient carbon emission reduction for each cluster type region: carbon high-high cluster areas are priority reduce emissions area, heighten energy saving technology and optimize industrial structure are two grippers to reduce emissions. Low - low carbon emissions concentrated area in western of Guangdong should primarily develop high and new technology industry. Low - low carbon emissions concentrated areas and high - high carbon emissions intensity concentrated area for eastern and northern of Guangdong province should try hard to wins ecological compensation at the same time focus on developing ecological tourism.
\end{abstract}

\section{Introduction}

In 2015, China promised to the international community to reduce its carbon intensity by $60-65$ percent on the basis of 2005levels by 2030 . The state decomposes the decline indicator of carbon emission intensity to each provinces, and the provinces decompose the indicators to prefecture-level cities. This top-down decomposition of large administrative divisions has been implemented for two "five years". In the process of implementing carbon emission reductions in various places, some prefecturelevel cities felt it difficult to effectively complete carbon emission reduction tasks because of unreasonable carbon emission reduction targets allocated by the province. This has resulted in a passive situation in which the overall efficiency of carbon emission reduction is low and completion is not good. A very important reason for this situation is that the effect of spatial effects is not considered in the process of decompose carbon emission reduction indicators, and the objective facts of carbon emissions in various regions have not been well described. The key to the formulation of efficient carbon emission reduction policies is to find the precise location of high carbon emission, and to formulate local and targeted carbon emission reduction policies based on the industrial characteristics of the region and surrounding areas. The spatial econometric method can be used to find the precise location of spatial carbon emission cluster area and heterogeneity area. Research results in this article can provide a theoretical reference for reasonable carbon emission reduction allocation plan and carbon emission reduction policy for Guangdong province.

\section{Introduction of spatial econometrics}

The biggest difference between spatial econometrics and traditional econometrics is the introduction of spatial effects. Spatial effects refer to the existence of a certain degree of spatial interaction between economic geography behaviors in various regions ${ }^{[1]}$. Anselin divides spatial effects into spatial dependence (also

\footnotetext{
* Corresponding author: caigt@ms.giec.ac.cn
} 
called spatial autocorrelation) and spatial heterogeneity [2]

(1) Spatial autocorrelation

Spatial autocorrelation considers that there is a closer relationship between variables that are closer together in space than those that are far apart ${ }^{[3-4]}$. It can be divided into global spatial autocorrelation and local spatial autocorrelation.

Global spatial autocorrelation: Global spatial autocorrelation is a description of the spatial characteristics of the observations of variables over the entire region, examining whether spatial phenomenon have an cluster effect over the entire region, it gives yes or no answer to above question. There are many indicators and methods for calculating global spatial autocorrelation, such as Moran's I, Geary's C, and GetiOrd. But the most commonly used one is the Global Moran's I proposed by Moran (1950) ${ }^{[5-8]}$.

Local spatial autocorrelation: Local spatial autocorrelation analysis can help us grasp the heterogeneity characteristics of spatial elements more accurately, and calculate the space position and range of the aggregation area. Local Indicators of Spatial Association (LISA) proposed by Anselin ${ }^{[9]}$ could measure the local spatial correlation and degree of difference between each spatial unit and its neighbors. For LISA analysis, you can get 4 different types of charts or maps: a significance map, a cluster map, a box map, and a Moran I scatter plot. The LISA cluster map essentially provides the same information as the significance map, except that the LISA significance map represent different levels of significance (different pvalues) with different colors, while in the LISA cluster map. Colors represent different spatial autocorrelation types. The cluster map shows four types of cluster, which are high-high $(\mathrm{H}-\mathrm{H})$ cluster areas (areas with high element values are surrounded by other areas with high values of same type elements). Low-low (L-L) cluster areas (areas with low element values are surrounded by other areas with low value of same type elements). Highlow (H-L) heterogeneity areas (areas with high factor values are surrounded by other areas with low values of same type elements). Low-high (LH) heterogeneity areas (areas with low element values are surrounded by other areas with high values of same type elements). The local spatial correlation analysis tell us where the abnormal value or Where the aggregation occurs, and answer the where question.

(2) Spatial heterogeneity

Spatial heterogeneity refers to the lack of homogeneity in the geospatial region, that is, the existence of central and peripheral regions, core and marginal regions, developed and backward regions, and other economic and geographical structures, this resulting in great spatial differences in economic and social development. For example, the high-low (H-L) heterogeneity areas and the low-high (L-H) heterogeneity areas in the LISA cluster map belong to this type of economic and geographical structures.

\section{Spatial econometrics research progress in carbon emission}

Domestic scholars have carried out some researches on space econometrics in the field of carbon emission. They have made some achievements, for example, the spatial dependence and temporal transition path of Chinese regional carbon emission were analyzed with global spatial autocorrelation testing and the spatial cluster was explored with local spatial autocorrelation testing by Tongxin etc. ${ }^{[10]}$. Zhaoyuntai etc. ${ }^{[11]}$ used Theil index and spatial autocorrelation analysis methods, the characteristics, regional disparity and spatial pattern evolution of carbon emission intensity from energy consumption were analyzed on national, regional and provincial level from 1999 to2007 in China. Chenzhijian etc. ${ }^{[12]}$ used spatial econometrics method analysis on the convergence characteristics of per capita carbon emissions in different region.Wuhong ${ }^{[13]}$ used the theory and method of spatial autocorrelation, calculated the global spatial autocorrelation index and local spatial autocorrelation index of China's provinces, revealed the evolution mechanism and action rules of carbon emission in the province. Liuxianzhaoetc. ${ }^{[14]}$, renxiaosongetc. ${ }^{[15]}$,longjiayongetc. ${ }^{[16]}$,xuhaiping ${ }^{[17]}$,yaoyi etc. ${ }^{[18]}$ also researched on spatial cluster and difference of national and provincial carbon emission. The above studies have reached a relatively consistent conclusion that both total carbon emission, per capita carbon emission, and carbon emission intensity have a certain degree of spatial autocorrelation and heterogeneity. The above researchers mostly stay at the national, provincial and other large-scale levels, and their research results are likely to cover up some more detailed scale and specific locations of local spatial autocorrelation and heterogeneity, which makes the spatial econometric methods fail to give full play to their strengths. A key factor that has not been explored on a more detailed scale is the difficulty of obtaining fine-scale energy consumption and carbon emission data.

In 2014, the author has studied the spatial autocorrelation of energy consumption carbon emission in Guangdong province ${ }^{[19]}$. The results show that total energy-related carbon emission and energy-related carbon emissions per capita exist significant global spatial autocorrelation from the year 2005to 2011. Energy-related carbon emission intensity not exist global spatial autocorrelation, but exist a low-low significant spatial autocorrelation local region in 2011. This article will carry out more detail scale research on energy carbon emissions, per capita carbon emissions and carbon intensity, namely research on energy carbon spatial econometric study in 125 counties of Guangdong province. We hope to find out concentrated area and the precise location of heterogeneous area of three kinds of carbon emissions targets. And provide decision basis and information support for Guangdong to make discrepant carbon emission reduction distribution plans and reduction policies. 


\section{Methods and data}

\subsection{Energy carbon emission accounting for 21 cities in Guangdong}

To guarantee the energy data integrity and data availability for 21 cities in Guangdong province, we have initiated two formulas to measure carbon emissions of the 21 cities, the formulas are as follows:

$$
\begin{aligned}
& C_{i}=E I_{i} \times G D P_{i} \times \text { Coe }_{\text {aver }} \\
& C o e_{\text {aver }}=\frac{C}{E}=\frac{\sum_{j} E_{j} \times C o e_{j}}{\sum_{i} E I_{i} \times G D P_{i}}
\end{aligned}
$$

In the formula, $E$ is the total amount of energy consumption in Guangdong province, $C$ is the total amount of carbon emissions produced by energy consumption; $i=1,2, \ldots 21$, represents the 21 prefecturelevel cities in Guangdong province, respectively. $C_{i}$ is carbon emission of $i$ city, and $E I_{i}$ is the energy consumption per unit of GDP of $i$ city. $C_{0} e_{\text {aver }}$ is the average carbon emission coefficient of Guangdong province, $j$ is energy type, $j=1,2 \ldots 18$, represents raw coal, washing coal,....., natural gas, 17types of energy sources, $\mathrm{Coe}_{j}$ is the carbon emission coefficient of $j$ energy, as shown in reference(wang,2011) ${ }^{[20]}$. The average carbon emission coefficient of Guangdong province calculated according to formula (2) is shown in table 1 .

Table 1. The average carbon emission coefficient of Guangdong province (tonC/ton standard coal)

\begin{tabular}{|c|l|l|l|l|}
\hline year & $\mathbf{2 0 0 5}$ & $\mathbf{2 0 0 6}$ & $\mathbf{2 0 0 7}$ & $\mathbf{2 0 0 8}$ \\
\hline $\begin{array}{c}\text { Coe } a v e r \\
\text { (ton C/ton standard coal) }\end{array}$ & 0.67 & 0.67 & 0.67 & 0.67 \\
\hline year & $\mathbf{2 0 0 9}$ & $\mathbf{2 0 1 0}$ & $\mathbf{2 0 1 1}$ & $\mathbf{2 0 1 2}$ \\
\hline $\begin{array}{c}\text { Coe } a v e r \\
\text { (ton C/ton standard coal) }\end{array}$ & 0.66 & 0.68 & 0.67 & 0.67 \\
\hline $\begin{array}{c}\text { year } \\
\text { Coe }\end{array}$ & $\mathbf{2 0 1 3}$ & $\mathbf{2 0 1 4}$ & $\mathbf{2 0 1 5}$ & $\mathbf{2 0 1 6}$ \\
\hline ton C/ton standard coal) & 0.66 & 0.66 & 0.65 & 0.64 \\
\hline
\end{tabular}

\subsection{Energy carbon emission accounting for district and county -level}

$C_{i k}=p_{i k} \times C_{i}$

In the formula, $C_{i k}$ is $i$ city $j$ district's total amount of carbon emission produced by energy consumption, $i=1$, $2, \ldots 21$, represents the 21 prefecture-level cities in Guangdong province, $k$ represents each district of $i$ city, $p_{i k}$ is $k$ district's energy consumption accounts for the proportion of the energy consumption of $i$ city, $C_{i}$ is carbon emission of $i$ city.In order to ensure the consistency of different spatial scale data, the energy consumption data of districts and towns are redistributed in proportion according to the data of prefecture-level cities.

\subsection{Data sources and processing}

The data used in this paper derived from Energy balance sheet of Guangdong Province in Chinese Energy Statistical Yearbook (2006-2017),the rests from Guangdong Statistical Yearbook (2006-2017) and China Statistical Yearbook (2006-2017) and Statistical Yearbook of 21prefecture-level cities correspondingly. To get rid of the effect from price changes, we converted the GDP at current price to the GDP at constant price in the year 2010 by using Indices of GDP (IGDP, preceding year=100).

\section{Results analysis}

\subsection{Global spatial autocorrelation analysis}

In 2005-2016, Moran's I of the total carbon emissions showed an increase trend year by year, indicate that the total carbon emissions have significant spatial autocorrelation, and the degree of autocorrelation is increased year by year. Moran's I of per capita carbon emission is decrease year by year, indicate that per capita carbon emission has significant spatial autocorrelation, but its autocorrelation degree is weaken year by year. The Moran's I of carbon emission intensity alternates between positive and negative values near zero, indicate that carbon emission intensity has no (or weak) global spatial autocorrelation. It can be seen that the three types of carbon emission indicators show different global spatial autocorrelation characteristics. Then, where are the significent cluster areas of total carbon emissions and per capita carbon emissions? Is there a local heterogeneity area? Where is its specific location? Whether there is a local spatial autocorrelation of carbon emission intensity, we will use data of 2005 and 2016 to find the answers to these questions from the analysis of local spatial autocorrelation

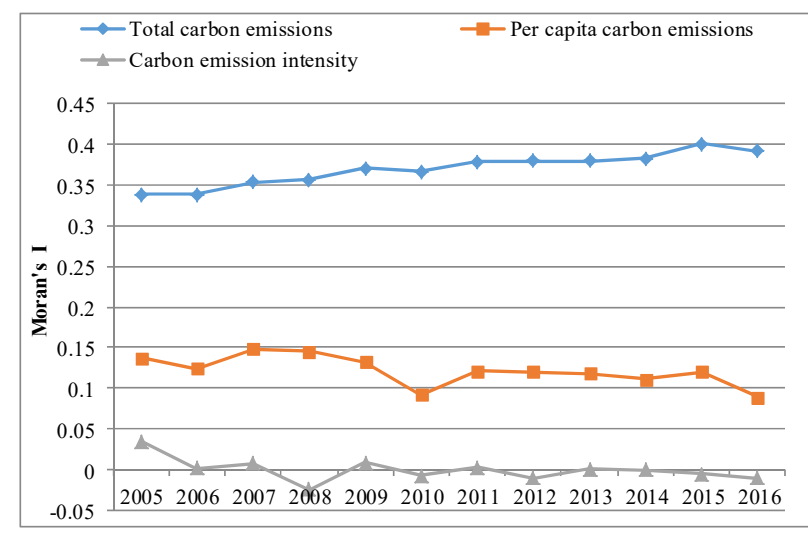

Fig.1. Change trends of Moran's I of three types of carbon emission indicators in 2005-2016

\subsection{Local spatial autocorrelation analysis}

(1) Analysis of the spatial distribution characteristics of total carbon emissions cluster and heterogeneity

It can be seen from table 2 and figure 2 that, in 2005 , the total carbon emissions high-high $(\mathrm{H}-\mathrm{H})$ significantly cluster areas are mainly from Baiyun district $(0.05,0.05$ means pass significance test,) Liwan district (0.01), 
Yuexiu district (0.05), Tianhe district (0.05), Panyu district (0.001), Zengcheng district (0.05) of Guangzhou city, Nanhai district $(0.05)$, Chancheng district $(0.05)$, Shunde district (0.05) of Foshan city, Dongguan City (0.01), Longgang district (0.01), Longhua district (0.01), Baoan district (0.001), Nanshan district (0.05) of Shenzhen city, Boluo county $(0.05)$ and Huicheng district $(0.05)$ of Huizhou city. There are totally 16 districts and counties. Meanwhile there are three significantly total carbon emissions low-low-cluster areas, which are located in the districts and counties of eastern and northern Guangdong. Among them, Dongyuan county(0.05), Lianping county (0.05) and Longchuan county $(0.05)$ of Heyuan city, Wuhua county $(0.01)$ of Meizhou city, Luhe county (0.05) of Shanwei city, and Jiexi county of Jieyang city (0.05) formed a significantly low-low cluster area in eastern Guangdong.
Fengkai county (0.05), Deqing county (0.05) and Huaiji county $(0.05)$ of Zhaoqing city formed a significantly low-low cluster area in northern Guangdong. What's more, Huazhou city of Maoming city (0.05), Lianjiang city (0.05), Wuchuan city (0.01). Leizhou city $(0.05)$ and Potou district (0.05) of Zhanjiang city formed a significantly low-low cluster area in western Guangdong. There are several prominent low-high heterogeneity areas inside the high-high cluster area of the Pearl River Delta, such as Luogang (0.001) and Huangpu district $(0.001)$ of Guangzhou city, Huiyang district $(0.05)$ of Huizhou city, Pengjiang district (0.05) of Jiangmen city. Guangming new district of Shenzhen (0.001).lastly, Meixian district of Meizhou city (0.05) and the Chikan district of Zhanjiang city (0.01) in the western Guangdong also formed significantly high-low heterogeneity areas.

Table 2. Detailed list of total carbon emission cluster areas and their significance levels in 2005 and 2016

\begin{tabular}{|c|c|c|c|c|c|c|}
\hline & & 2005 & & & 2016 & \\
\hline $\begin{array}{c}\text { Cluster } \\
\text { type }\end{array}$ & $\begin{array}{c}\text { The } \\
\text { prefecture- } \\
\text { level city }\end{array}$ & $\begin{array}{c}\text { District or } \\
\text { county }\end{array}$ & $\begin{array}{c}\text { p-value } \\
\text { (significance } \\
\text { test), }\end{array}$ & $\begin{array}{c}\text { prefecture- } \\
\text { level city }\end{array}$ & $\begin{array}{l}\text { District or } \\
\text { county, }\end{array}$ & $\begin{array}{c}\text { p-value } \\
\text { (significance } \\
\text { test) }\end{array}$ \\
\hline \multirow{18}{*}{$\begin{array}{c}\text { High-High } \\
\text { Cluster Area } \\
(\mathrm{H}-\mathrm{H})\end{array}$} & \multirow{8}{*}{ Guangzhou } & Baiyun & 0.05 & \multirow{8}{*}{ Guangzhou } & Baiyun & 0.05 \\
\hline & & Li Wan & 0.01 & & Li Wan & 0.01 \\
\hline & & Yuexiu & 0.05 & & Yuexiu & 0.05 \\
\hline & & Tianhe & 0.05 & & Tianhe & 0.05 \\
\hline & & Panyu & 0.001 & & Panyu & 0.001 \\
\hline & & Zengcheng & 0.05 & & Zengcheng & 0.05 \\
\hline & & & & & Haizhu & 0.05 \\
\hline & & & & & Huadu & 0.05 \\
\hline & \multirow{3}{*}{ Foshan } & Nanhai & 0.05 & \multirow{3}{*}{ Foshan } & Nanhai & 0.05 \\
\hline & & Chancheng & 0.05 & & Chancheng & 0.05 \\
\hline & & Shunde & 0.05 & & Shunde & 0.01 \\
\hline & Dongguan & Dongguan & 0.01 & Dongguan & Dongguan & 0.001 \\
\hline & \multirow{4}{*}{ Shenzhen } & Longgang & 0.01 & \multirow{4}{*}{ Shenzhen } & Longgang & 0.01 \\
\hline & & Longhua & 0.01 & & Longhua & 0.001 \\
\hline & & Bao'an & 0.001 & & Bao'an & 0.01 \\
\hline & & Nanshan & 0.05 & & Nanshan & 0.05 \\
\hline & \multirow[t]{2}{*}{ Huizhou } & $\begin{array}{l}\text { Boluo } \\
\text { county }\end{array}$ & 0.05 & \multirow[t]{2}{*}{ Huizhou } & Huiyang & 0.01 \\
\hline & & Huicheng & 0.05 & & Huicheng & 0.01 \\
\hline \multirow{5}{*}{$\begin{array}{l}\text { Low-high } \\
\text { heterogeneity } \\
\text { area }(\mathrm{L}-\mathrm{H})\end{array}$} & \multirow{2}{*}{ Guangzhou } & Luogang & 0.001 & \multirow{2}{*}{ Guangzhou } & Luogang & 0.001 \\
\hline & & Huangpu & 0.001 & & Huangpu & 0.01 \\
\hline & Huizhou & Huiyang & 0.05 & Huizhou & Boluo county & 0.05 \\
\hline & Jiangmen & Pengjiang & 0.05 & Jiangmen & Pengjiang & 0.05 \\
\hline & Shenzhen & $\begin{array}{c}\text { Guangming } \\
\text { New district }\end{array}$ & 0.001 & Shenzhen & Guangming new district & 0.001 \\
\hline \multirow{2}{*}{$\begin{array}{l}\text { High-low } \\
\text { heterogeneity } \\
\text { area (H-L) }\end{array}$} & Meizhou & Meixian & 0.05 & & & \\
\hline & Zhanjiang & Chikan & 0.01 & & & \\
\hline \multirow{8}{*}{$\begin{array}{c}\text { Low-low } \\
\text { cluster area } \\
\text { (L-L) }\end{array}$} & \multirow{4}{*}{ Heyuan } & $\begin{array}{l}\text { Dongyuan } \\
\text { county }\end{array}$ & 0.05 & \multirow{4}{*}{ Heyuan } & Dongyuan county & 0.05 \\
\hline & & $\begin{array}{l}\text { Lianping } \\
\text { county }\end{array}$ & 0.05 & & Lianping county & 0.05 \\
\hline & & $\begin{array}{c}\text { Longchuan } \\
\text { county }\end{array}$ & 0.05 & & Longchuan county & 0.05 \\
\hline & & & & & Heping county & 0.05 \\
\hline & Meizhou & $\begin{array}{l}\text { Wuhua } \\
\text { county }\end{array}$ & 0.01 & Meizhou & Wuhua county & 0.01 \\
\hline & Shanwei & $\begin{array}{l}\text { Luhe } \\
\text { county }\end{array}$ & 0.05 & Shanwei & Luhe county & 0.001 \\
\hline & Jieyang & Jiexi county & 0.05 & Jieyang & Jiexi county & 0.05 \\
\hline & Zhaoging & Fengkai & 0.05 & Zhaoqing & Fengkai county & 0.05 \\
\hline
\end{tabular}




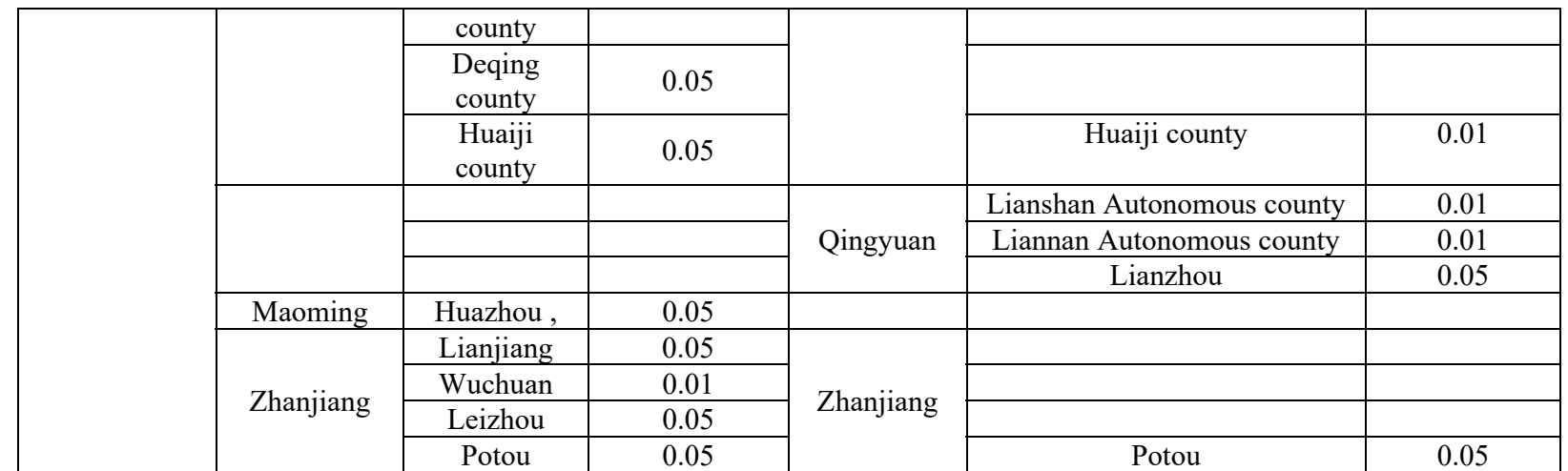

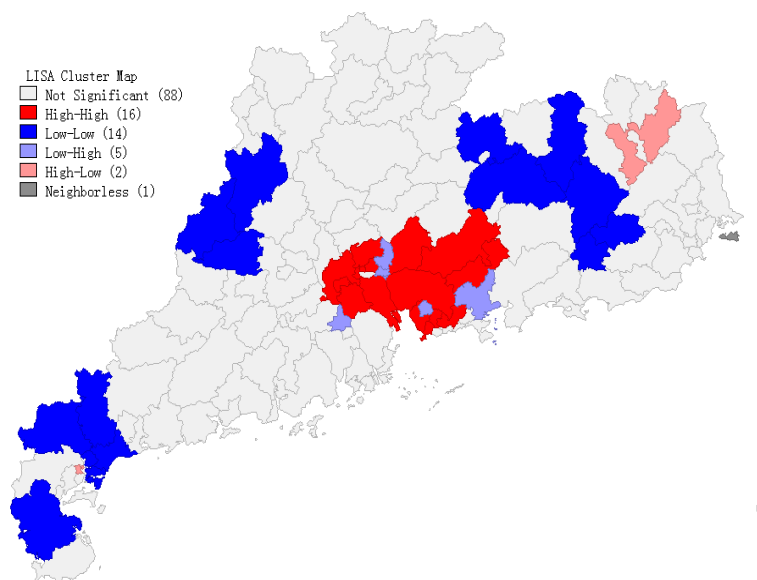

2005

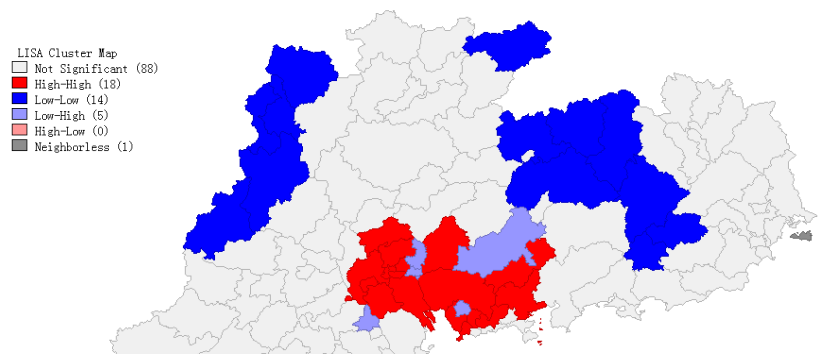

Fig.2. LISA Cluster map of total carbon emissions in the year 2005 and 2016

Compared with 2005, there are two main changes in the spatial distribution pattern of total carbon emissions cluster and heterogeneity areas in 2016: one is the disappearance of high-low heterogeneity areas, and the other is that the significantly low-low cluster areas in western Guangdong have reduced to one district --Putou district of Zhanjiang city, and significantly low-low cluster areas in northern Guangdong and eastern Guangdong is expanding. At the same time, the highhigh cluster area in the Pearl River Delta is also expanding, indicating that the spatial dependence of total carbon emissions in the Pearl River Delta, northern Guangdong and eastern Guangdong is gradually increasing, and the spatial dependence of carbon emissions in the western Guangdong is gradually weakening. Overall, the spatial dependence of total carbon emissions in Guangdong province has increased year by year, we can also conclude it from increase in Moran's I value year by year.

(2) Analysis of spatial distribution characteristics of per capita carbon emissions cluster and heterogeneity areas

It can be seen from table 3 and figure 3 shows that,in 2005, per capita carbon emissions high-high significantly cluster $(\mathrm{HH})$ areas were distributed in the Baiyun district (0.05), Luogang district (0.05), Tianhe district (0.05), Yuexiu district (0.05), Liwan district (0.05), Panyu district (0.05), Huangpu district (0.05) and

Haizhu district (0.05) of Guangzhou city, Dongguan city (0.05) and Nanhai district of Foshan city (0.05). There are three significantly per capita carbon emissions low-low cluster areas, which are located in the districts and counties of northern,western and eastern Guangdong. Among them, Dongyuan (0.05) and Longchuan county

Table 3. Detailed list of per capita carbon emission Cluster areas and their significance levels in 2005 and 2016

\begin{tabular}{|c|c|c|c|c|c|c|}
\hline & \multicolumn{3}{|c|}{2005} & \multicolumn{3}{|c|}{2016} \\
\hline $\begin{array}{l}\text { Cluster } \\
\text { type }\end{array}$ & $\begin{array}{l}\text { The } \\
\text { prefecture- } \\
\text { level city }\end{array}$ & District or county & $\begin{array}{c}p \text {-value } \\
\text { (significance test) }\end{array}$ & $\begin{array}{c}\text { The } \\
\text { prefecture- } \\
\text { level city }\end{array}$ & $\begin{array}{l}\text { District or } \\
\text { county }\end{array}$ & $\begin{array}{c}\text { p-value } \\
\text { (significance } \\
\text { test) }\end{array}$ \\
\hline \multirow{9}{*}{$\begin{array}{c}\text { High-High } \\
\text { Cluster Area } \\
(\mathrm{H}-\mathrm{H})\end{array}$} & \multirow{8}{*}{ Guangzhou } & Baiyun & 0.05 & & & \\
\hline & & Luogang & 0.05 & & & \\
\hline & & Tianhe & 0.05 & & & \\
\hline & & Yuexiu & 0.05 & & & \\
\hline & & Li Wan & 0.05 & & & \\
\hline & & Panyu & 0.05 & & & \\
\hline & & Huangpu & 0.05 & & & \\
\hline & & Haizhu & 0.05 & & & \\
\hline & Foshan & Nanhai & 0.05 & Foshan & & \\
\hline
\end{tabular}




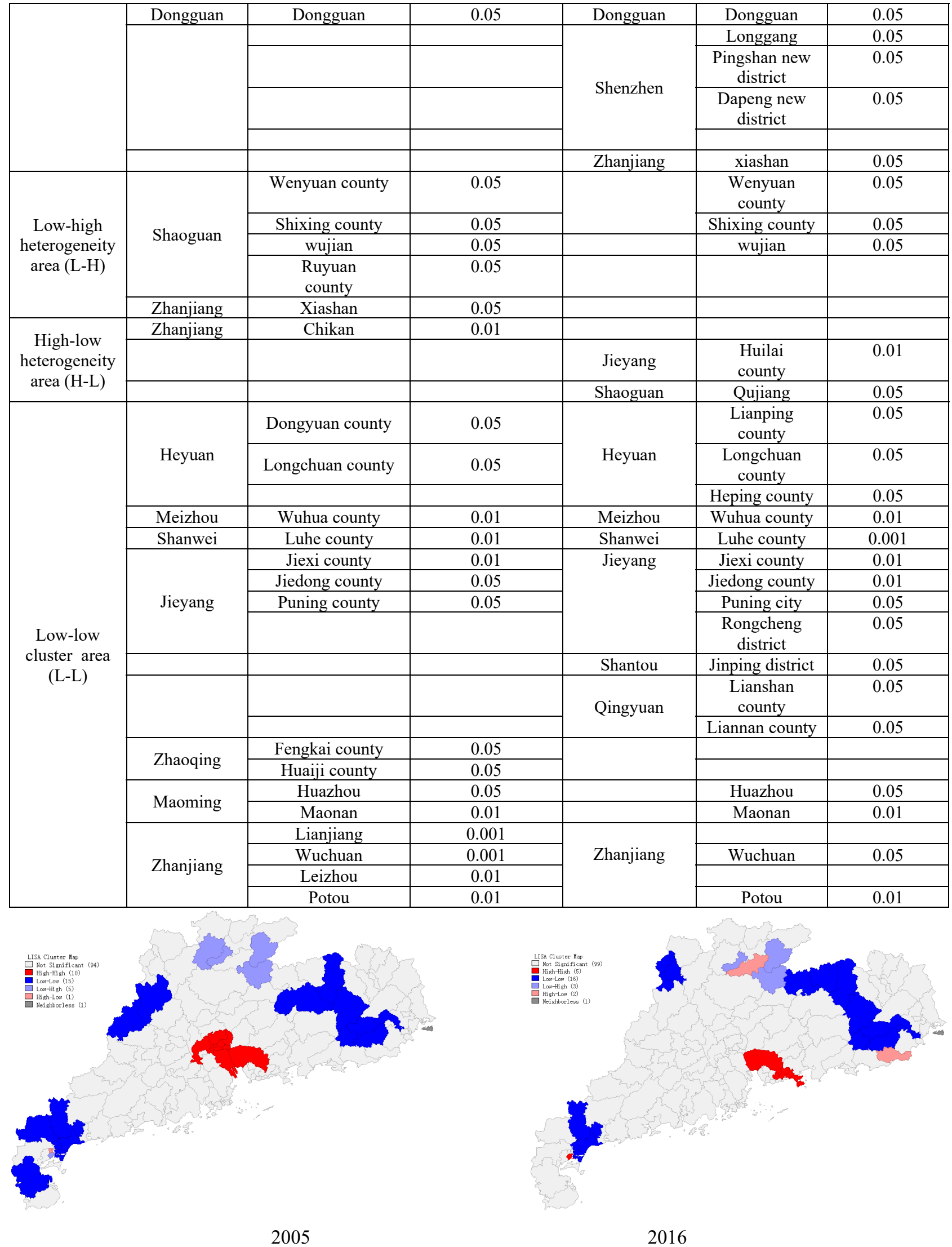

Fig.3. LISA cluster map of per capita carbon emissions in the year 2005 and 2016

(0.05) of Heyuan city, Wuhua county (0.01) of Meizhou city, Luhe county (0.01) of Shanwei city, and Jiexi (0.01) and Jiedong county of Jieyang city (0.05) and Puning city $(0.05)$ formed a significantly low-low cluster area in eastern Guangdong. Fengkai (0.05) and
Huaiji county (0.05) of Zhaoqing city formed a significantly low-low cluster area in northern Guangdong. Huazhou (0.05), Maonan (0.01), Lianjiang (0.001), Wuchuan (0.001), Leizhou city (0.01) and Potou district (0.01) of Zhanjiang city are significantly low-low 
cluster area in western Guangdong. There are two significantly low-high heterogeneity areas, one consisting of Wengyuan

(0.05), Shixing (0.05), Wujiang (0.05) and Ruyuan Autonomous county (0.05)of Shaoguan city in Northeastern Guangdong. The other is in Xiashan (0.05) of Zhanjiang city in Western Guangdong. Correspondingly, a significantly high-low heterogeneity area (0.01) was formed in the Chikan district next to the Xiashan district. It can be seen that the high-low heterogeneity area and the low-high heterogeneity area may be reciprocal causation and appear simultaneously.

Compared with 2005, there are two obvious changes in the spatial distribution pattern of per capita carbon emissions cluster and heterogeneity areas in 2016: one is a significantly increase of high-low heterogeneity, for example, the Qujiang district of Shaoguan city and Huilai county of Jieyang city formed two significantly high-low heterogeneity areas. The other is that the range of significantly high-high cluster areas and significantly low-low cluster areas are shrinking. This shows that the degree of per capita carbon emissions spatial cluster is weakening, and heterogeneity is increasing, which can be also seen from decline of Moran's I value year by year.
(3) Analysis of the spatial distribution characteristics of carbon emission intensity cluster and heterogeneity

It can be seen from table 4 and figure 4 that, in 2005, there was one carbon emission intensity significantly high -high cluster area $(\mathrm{H}-\mathrm{H})$, that is Yingde $(0.05)$ of Qingyuan city. There are two significantly carbon emission intensity low-low cluster areas, one is the significantly low-low cluster area in western Guangdong formed by Lianjiang (0.01), Wuchuan (0.01), Tunxi county (0.01), Leizhou (0.01) and Potou (0.01) of Zhanjiang city. Huazhou (0.05) and Maonan city $(0.01)$ of Maoming city. The other is a significantly low-low cluster area in eastern Guangdong formed by Jiexi county $(0.05)$ of Jieyang city. Meanwhile, There are two significantly low-high heterogeneity areas, one is the significantly low- high heterogeneity area in northern Guangdong formed by Wengyuan (0.05), Shixing (0.05), Wujiang (0.05) and Ruyuan Autonomous county (0.01)of Shaoguan city. The other is the significently low-high heterogeneity areas in eastern Guangdong formed by Pingyuan county (0.05) of Meizhou city. There is also one significantly high-low heterogeneity area in western Guangdong, which located in Chikan district (0.01) of Zhanjiang city.

Table 4. Detailed list of carbon emission intensity cluster areas and their significance levels in 2005 and 2016

\begin{tabular}{|c|c|c|c|c|c|c|}
\hline & \multicolumn{3}{|c|}{2005} & \multicolumn{3}{|c|}{2016} \\
\hline Cluster type & $\begin{array}{c}\text { The } \\
\text { prefecture- } \\
\text { level city }\end{array}$ & $\begin{array}{l}\text { District or } \\
\text { county }\end{array}$ & $\begin{array}{c}\text { p-value } \\
\text { (significance } \\
\text { test) }\end{array}$ & $\begin{array}{c}\text { The } \\
\text { prefecture- } \\
\text { level city }\end{array}$ & $\begin{array}{l}\text { District or } \\
\text { county }\end{array}$ & $\begin{array}{c}\text { p-value } \\
\text { (significance } \\
\text { test) }\end{array}$ \\
\hline \multirow{2}{*}{$\begin{array}{c}\text { High-High } \\
\text { Cluster Area } \\
(\mathrm{H}-\mathrm{H})\end{array}$} & Qingyuan & Yingde city & 0.05 & Qingyuan & Yingde city & 0.05 \\
\hline & & & & Meizhou & Pingyuan county & 0.05 \\
\hline \multirow{7}{*}{$\begin{array}{l}\text { Low-high } \\
\text { heterogeneity } \\
\text { area }(\mathrm{L}-\mathrm{H})\end{array}$} & \multirow{5}{*}{ Shaoguan } & $\begin{array}{c}\text { Ruyuan } \\
\text { Autonomous } \\
\text { county } \\
\end{array}$ & 0.01 & \multirow{5}{*}{ Shaoguan } & $\begin{array}{c}\text { Ruyuan } \\
\text { Autonomous } \\
\text { county }\end{array}$ & 0.01 \\
\hline & & Wujiang & 0.05 & & Wujiang & 0.05 \\
\hline & & $\begin{array}{c}\text { Wengyuan } \\
\text { county }\end{array}$ & 0.05 & & Wengyuan county & 0.05 \\
\hline & & Shixing county & 0.05 & & Shixing county & 0.05 \\
\hline & & & & & Qujiang & 0.05 \\
\hline & Meizhou & $\begin{array}{c}\text { Pingyuan } \\
\text { county }\end{array}$ & 0.05 & & & \\
\hline & & & & Yunfu & Yunan county & 0.05 \\
\hline $\begin{array}{c}\text { High-low } \\
\text { heterogeneity } \\
\text { area }(\mathrm{H}-\mathrm{L})\end{array}$ & Zhanjiang & Chikan & 0.01 & Zhanjiang & Chikan & 0.05 \\
\hline \multirow{9}{*}{$\begin{array}{c}\text { Low-low } \\
\text { cluster area } \\
\text { (L-L) }\end{array}$} & Jieyang & Jiexi county & 0.05 & & & \\
\hline & & & & Shanwei & Luhe county & 0.01 \\
\hline & \multirow{2}{*}{ Maoming } & Huazhou city & 0.05 & \multirow{2}{*}{ Maoming } & Huazhou city & 0.05 \\
\hline & & Maonan & 0.01 & & Maonan & 0.05 \\
\hline & \multirow{5}{*}{ Zhanjiang } & Lianjiang city & 0.01 & \multirow{5}{*}{ Zhanjiang } & Lianjiang city & 0.05 \\
\hline & & Wuchuan city & 0.01 & & Wuchuan city & 0.05 \\
\hline & & Suixi county & 0.01 & & Suixi county & 0.05 \\
\hline & & Leizhou city & 0.01 & & Leizhou city & 0.05 \\
\hline & & Potou & 0.01 & & Potou & 0.05 \\
\hline
\end{tabular}

Compared with 2005, there are two main changes in the spatial distribution pattern of carbon emission intensity cluster and heterogeneity area in 2016: one is that Pingyuan county of Meizhou city has changed from a significantly high-low heterogeneity area to a significantly high-high heterogeneity area. The other is the expansion of the low-high heterogeneity area, the Qianjiang district of Shaoguan city has developed into significantly low-high heterogeneity areas. In addition, Yunan county of Yunyun city has also turned into a 
significantly low-high heterogeneity area. This change indicates that the spatial cluster and

heterogeneity of carbon emission intensity show the trend of polarization, resulting in the alternating occurrence of positive and negative global Moran's I. when we look from the perspective of global autocorrelation, the carbon emission intensity seems to be irrelevant. In fact, there is a significant local correlation. So it is verified that the local autocorrelation analysis could actually find the local spatial characteristics which cannot be detected by the global spatial autocorrelation analysis.

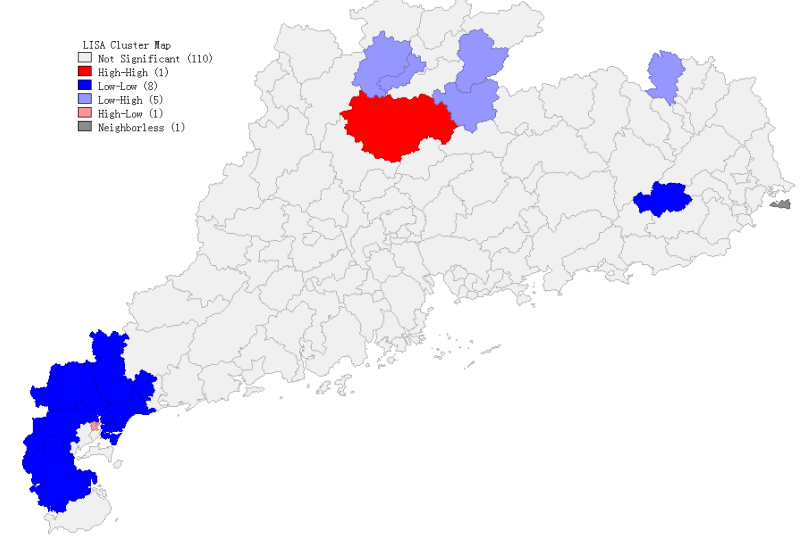

2005

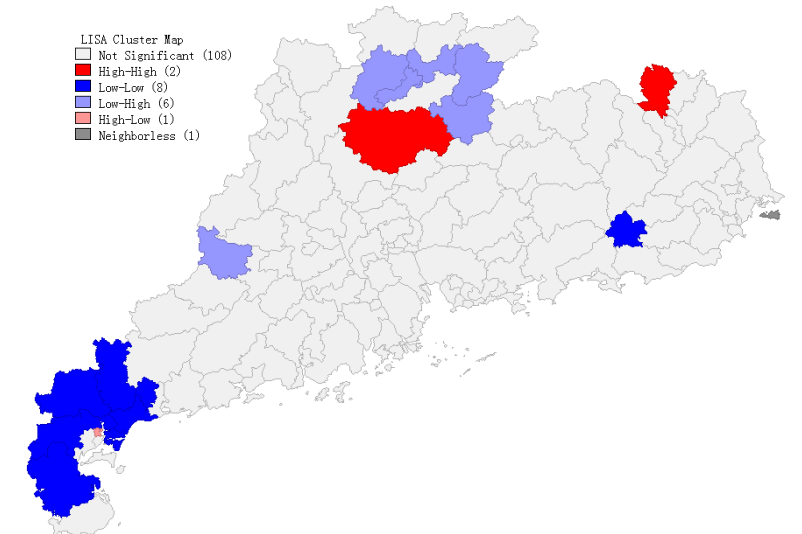

2016

Fig.4. LISA cluster map of carbon emission intensity in the year 2005 and 2016

\section{Policy recommendations on carbon emission reduction in different cluster areas}

\subsection{High-high cluster areas should give priority to carbon emission reduction and consider adopting technology and optimizing industrial structure to be two main solutions}

Cluster areas where total carbon emissions and per capita carbon emissions are both high are mainly in several districts and counties of Guangzhou, Dongguan and Shenzhen in Pearl River Delta. These districts and counties are typical economically developed areas, though their carbon emissions intensity is already relatively low. However, due to their large economic base, it will have a significant impact on the decline of carbon emissions increment in the whole province if carbon emissions intensity drops by one percentage. So priority should be given to carbon emission reduction in these areas, they are the key areas for energy-saving and carbon emission reduction. These areas should work on developing energy-saving technology and optimizing industrial structure. For example, introduce more investment and develop advanced energy-saving technology, require local factories to replace old equipment with efficient and advanced equipment, urge the transfer of high energy-consuming industries and introduce hi-tech industries and so on.

\subsection{Carbon emissions Low-low cluster area in western Guangdong should primarily develop hi-tech industries}

Maonan District of Maoming City and Lianjiang. Wuchuan and Potou District of Zhanjiang City in western Guangdong are the key development districts of the main functional areas. Especially for the Zhanjiang City, it is the central city of western Guangdong and an important coastal open city in China, its momentum of development is quite strong with the favorable policies of the main functional areas. During the 13th five-year plan period, major energy-consuming projects such as Baogang Zhanjiang steel production Base; Zhongke rrefining and chemical integration program; Chenming Paper production program; Leizhou Datang Power Plant program and a number of upstream and downstream industrial chain supporting projects were successively cluster, It drove the total energy consumption of Zhanjiang City increase sharply, and meanwhile carbon emissions also increased quickly. But according to the present situation, three carbon emission indicators of total carbon emissions, per capita carbon emissions and carbon emission intensity all suggest significantly low within carbon emissions cluster areas in these districts and counties. Therefore, these districts and counties should take moderate energy-saving measures in rapid development of economy. They should be alert to the arrival of the era of high carbon emissions with the rapid economic development and make the characteristics of the low-low cluster areas unchanged.

\section{3 carbon emissions low-low cluster areas and carbon emissions intensity high - high cluster areas in northeast Guangdong should protect environment and focus on developing ecological tourism}

Most of the regions in northeast Guangdong are national or provincial key ecological functional areas, these regions own a large carbon emissions significantly lowlow cluster areas and some low-high or high-low heterogeneity areas. The carbon emission intensity of these regions is higher than that of developed regions due to their relatively backward economic development, such as carbon emission intensity high-high cluster area 
in Yingde of Qingyuan City and Pingyuan County of Meizhou City. So it is the key for these regions to greatly increase the size of the economy in order to reduce carbon emission intensity. There are two main ways to achieve that goal. One way is to protect the ecological environment and strive for ecological compensation as much as possible with the opportunity of advocating regional development coordination in Guangdong Province. The other way is to develop ecological tourism, these regions could make full use of ecological advantages to gain economic benefits by learning the successful experience from domestic and international ecological development districts. These solutions could not only maintain or expand the range of low-low carbon emissions cluster areas, but also makes the high-low heterogeneity areas to disappear or develop into low-low cluster areas.

\section{Acknowledgments}

This work has benefitted from the support of provincial science and technology plan project of Guangdong province (2018A050501011) and Guangdong special project on low-carbon development (GPCGD163104FG357F)

\section{References}

1. J. Hu,B. Jiao. Statistics \& Information Forum27, 3$8(2012)$

2. A.Luc, D.A. Griffith.P.R.S.A.65, 11-34(1988)

3. R. R.Sokal, N.L.Oden. Bio. J Linn Soc10, 199228(1978)

4. X.NLiu,F.huang, P.wang. GIS spatial analysis principle and method.Beijing, science press(2005)

5. Y.M.Wu.Spatial econometric analysis of the difference between economic growth and income distribution in China,Beijing: Economic science press, 322-325(2005)

6. B.Meng, J.F.Wang, W.Z.Zhang, X.H.Liu. Sci. G.S.25,393-400(2005)

7. C.S.Tian,M.Gai. Jour.D.B.U.F.E. 87-90(2004).

8. Y.M.Wu, J.H.Xu .Sci.G.S. 24,654-659(2004)

9. L.Anselin. Geo.A.27,93-115(1995)

10. X. Tong , X.S. Li , L.Tong , K.Chen.Jou.N.U.( Natural Science)37,16681672(2016)

11. Y.T.Zhao, X.J.Huang, T.Y. Zhong, J.W. Peng.Envir.S.32,3145-3152(2011)

12. Z.J.Chen,Z.Wang, Y. Sun. Jour.A.L.R.E.29, $24-$ 29(2015)

13. H.Wu. Man.W., 3-10(2015)

14. X.Z.Liu,C.C. Gao,Y.Zhang,G.H.Yu,Y.Song. Jour.A.L.R. E.30,1-6(2016)

15. X.S.Ren, T.Zhao. Jour.A.L.R.E.28, 6-10(2014)

16. J.Y.Long, C.Z.Wu,W.Hong,J.Y. Lin.Eco.Eco., 49-
53(2011)

17. H.P.Xu..Chi.P.R.E.22, 149-157(2012)

18. Y.Yao, Q.Ni,Eco.Geo.31,1432-1438(2011)

19. W.X.Wang, Y.Q.Kuang, N.S.Huang.Envir.S.\& Tech.37,180-187(2014)

20. W.X.Wang, Y.Q.Kuang, N.S.Huang. Energies4, 2249-2272(2011) 